DOI https://doi.org/10.30525/978-9934-26-000-1-20

\title{
MEDIA CULTURE AS A FACTOR OF MOLDING INFORMATION ETHICS IN THE DIGITAL SOCIETY
}

\author{
Kyianytsia Ye. O. \\ Candidate of Sciences in Social Communications, \\ Associate Professor at the Department of Journalism and Advertising \\ Kyiv National University of Trade and Economics \\ Kyiv, Ukraine
}

The modern world, with its multitasking, speed of technological change, challenges to new ideas and analogies, contributes to the various understanding of the content and meaning of transmitted information, generates inadequate perception of cultural values. Thus, modern socio-cultural conditions, to some extent, change the meaning of the categories "culture" and "information". The understanding of culture as the unity of the material and spiritual life of society is gradually being replaced in favor of convergent media that broadcast customized cultural content. The saturation of modern society with information, mobile and flexible socio-cultural dynamics requires a deep cultural rethinking. The solution to this problem can be made through the analysis of culture as an information system, as well as understanding the processes of deep socio-economic transformations, the specifics of which can as encourage adaptive defense mechanisms of traditional culture as level down traditions to form a new technological culture.

However, today, with all the variety of formulations, the concept of "information culture" has an equivocal structure and is characterized by differrent components. Meanwhile the concept itself is already used actively in science and is a potential area of research, especially in modern communication practice. Those today are most actively moving into the digital space as the factor that determines the development of all spheres of culture and society as a whole are new technologies. The center of cultural dynamics is gradually moving more and more from the spiritual sphere to technological culture, respectively, the question arises of the appropriateness of such transformations. In this regard, A.S. Carmine notes: "When the society raises the level of technological culture without caring about spiritual culture it threatens to reduce the level of spiritual values in it" [2, p. 59]. Not only modern information culture, being part of the general personal culture and an integral part of the information society, requires comprehensive study but together with consideration of the phenomenon of media culture, which is an instrument of social control and the driving force of consumerism.

We should emphasize the multiplicity and complexity of the definition of media culture as such, for its basis is the combination of the concepts of 
"media" and "culture", which in turn can be interpreted as the culture of media professionals. But it is not possible for us to limit ourselves to such interpretation, because medical culture can be considered as a socio-cultural situation in society, as well as a certain characteristic of the environment, or as a layer between the society and the government, and as a way of perceiving the world. Given this phenomenon is vague and simultaneously consistent with other scientific and practical areas including ethical norms, moral values, educational attitudes, we have to agree with S.K. Shaikhitdinova. She emphasizes: "if the media is associated with the subject area which purpose is to ensure the transmission of cultural meanings then media culture is ubiquitous; its definition coincides with the definition of culture as a whole" [6, p. 191].

Media culture is a new concept that involves the culture of information transfer, as well as the culture of its consumption. It can act as a system of levels of personal development, capable to perceiving, analyzing and evaluating media texts, media creativity, ingraining new knowledge in the field of media. An important step of the new media culture is developing the skills of cultural discussion and understanding of how the traditions of the country, religion, ethnic and social groups as well as beliefs, symbols and existing means of communication affect the creation, dissemination and consumption of information.

One of the bright and popular means of media culture are social networks, blogs, vlogs, YouTube channels. Designing them the developers focus on the average taste trying to predict the requests and preferences of future users. Such manifestations of media culture contribute to shaping the consumer of information not as a person but as a molded image with an everlasting desire of comparing and discussing themselves with others, critical statements and popularizing their own selfishness, i.e. all that contradicts generally accepted moral principles. Thus, audiences themselves choose the information simplified for their perception, so as not to take pains for further reflection.

Today we are witnessing such trends in the consumption of cultural values as a decrease in the audience of conceptual works of art compared to mass media content. These trends are conditioned by the fact that each owner of the gadget can be a media content maker, allegedly for this, one does not need to have a special education or a large budget - it is available through the development of technology. But the development of information technologies does not exhaust the need to comprehend the impact of media culture on the development of the information society. It is also necessary to understand the fact of continuous knowledge update, advanced training, development of new activities, creation of new cultural values.

At the same time, the inconsistency of the structure of media culture, the absence of understanding of its advantages and disadvantages, poor algorithms for its formation and implementation, impose an additional problem 
to a person, offering them simultaneously to work out research instruments and adapt to low cultural levels. That is, in the media environment today there is a tendency to adjust cultural values to the existing needs of the audience, but not raise consciousness and intelligence in order to improve the cultural level of the audience.

Informational influence plays an important role in the processes of both the formation and destruction of personal dispositions. Today therefore, a person needs the ability and desire to maintain in good working condition their cognitive sphere: the ability to develop analytical skills concerning the information circulating in the society, the ability to fix beliefs and opinions, and if necessary, correlate them, consolidate and increase knowledge.

Nowadays, media culture is becoming an integral part of social everyday life and, in a sense, a religion that needs its own virtues. Despite the possible shortcomings due to the lack of legal and legislative norms, as well as limited personal attitudes to the observance of moral values, we should emphasize the positive aspects of such a phenomenon as digital media culture, namely:

- quickness of obtaining information about world events;

- relaxation of cultural barriers, intercultural dialogue;

- opportunity to gain new knowledge (online courses, trainings, master classes, coaching, etc.)

- visualization of the creativity results, which become the belonging of all mankind, not a separate nation;

- development and accessibility of media art to the general public.

Given the positive features that media culture shows us, it is necessary to understand that it should be based on ethics, not manipulation as a way of domination and suppression of the will, because psychological violence against a person is as much encroaching on freedom and human rights as physical violence. True culture, in whatever form presented, cannot be oppressive, otherwise it ceases to play its main role - the transmission of actual social experience, which should involve not only state legislatures, science and education, but also public structures, mass media with its great potential for dissemination of information.

Thus, in cultural and artistic media products, the emphasis should be made on the formation of the audience's ability to assimilate meaningfully media content based on the knowledge of the specifics and goals of mass communication. It is necessary to pay more attention to the development of independent critical thinking in relation to the media, to acquire practical skills of detecting true or distorted information, to develop lasting immunity against the manipulative influence of the media, to enrich human social and cultural practice $[5, \mathrm{p} .156]$.

To sum up, we should note that the development and broadcasting of cultural and artistic media products contributes to the expansion of the field of scientific discourse on the formation of media culture. Specifically, the 
discourse being debated about understanding interaction of individuals in the media environment moves to the forefront the issues of media culture, media ethics, media literacy in today's information and digital society.

In these conditions, it is an important task to preserve the cultural identity of an individual, their socialization in the culture of media reality, defining the boundaries between self-presentation, simulation and selfactualization of a person in the modern media space.

\section{References:}

1. Valyansky S.I., Kalyuzhny D.S. Another history of science. M. : IMFRA-M., 2002. № 6. Pp. 13-19.

2. Carmine A.S. Philosophy of culture in the informational society: problems and prospects. Questions of philosophy 2006. № 2. P. 59.

3. Kirillova N.B. Media culture and basics of media management. : [manual]. Ekaterinburg: Ural Publishing House. University, 2014. 184 p.

4. Kholod O.M. Social communications: socio and psycholinguistic analysis: textbook. manual. 2nd ed., Ext. and rev. Lviv: PAIS, 2011. 288 p.

5. Chelysheva I.V. Sociocultural field of media: reality, communication, man. M: MOO "Information for all", 2016. $178 \mathrm{p}$.

6. Shaikhitdinova S.K. Vectors of Media Culture. Kazan: Scientific notes of Kazan University. 2013. Volume 155. Book. 1. Pp. 189-198

7. Program Manifesto "Culture - Media - Theology". Kwartalnik Naukowy «Kultura Media Teologia». Access link: https://kmt.uksw.edu.pl/ manifest-tekst 